\title{
Conditions, demands and constraints on trainers' activity: a case study in the Portuguese context
}

\author{
Marta Santos ${ }^{\mathrm{a},},{ }^{*}$ and Andreia Ferreira ${ }^{\mathrm{b}}$ \\ ${ }^{a}$ Centro de Psicologia da Universidade do Porto, Faculdade de Psicologia e de Ciências da Educação, \\ Universidade do Porto, Alfredo Allen, 4200-135 Porto, Portugal \\ ${ }^{b}$, Faculdade de Psicologia e de Ciências da Educação, Universidade do Porto, Alfredo Allen, 4200-135 Porto, \\ Portugal
}

\begin{abstract}
The aim of the present study is to contribute to the analysis of employment and work conditions of Portuguese trainers, as well as to identify conditions, resources, demands and constraints of their work activities. Despite the lack of scientific knowledge on professional training, the topic has been playing a central role in modern societies. Several data collection strategies were used, namely the application of INSAT to 72 trainers, exploratory interviews with 10 trainers and collective interviews with 6 trainers. The analysis of the data collected highlights the changes in the selection of human resources in the sector as well as the contractual terms of the trainers, mainly independent workers. The intra and inter individual variability of working hours and the diversity of activities performed by each trainer also stands out. Finally, it is important to refer the spontaneous organization of trainers' work activities according to their training modality.
\end{abstract}

Keywords: trainers' activity, working conditions, health

\section{Introduction}

Professional training has been playing a central role in modern society. Some hope that it will be the answer for the existing economic and social problems. In an attempt to respond to this demand, in recent years professional training has changed and diversified its fields of action, mainly to, "increase the competitiveness of companies, keep up their restructuring processes and fight against unemployment" [7]. The Portuguese situation is not an exception and, in 2005, the initiative New Opportunities was launched with the objective of qualifying 1.000 .000 active adults by 2010 , with a reference level of secondary school graduation (equivalent to the attendance of 12 years of regular schooling) [2].

Nevertheless, the scientific knowledge of the trainers' activity is still limited and directed towards a fragmented and diversified professional group [6, $7,10]$. The aim of this paper is to present a study focused on the role of the Portuguese trainer, contributing to the analysis of employment and working conditions as well as identifying the conditions, resources, demands and constraints of their work activity.

\subsection{Literature review}

Notwithstanding the increasing interest of the scientific community, trainers are still a difficult group to define and are frequently classified as invisible, segmented, diversified [16], as well as associated to the notions of polyvalence, instability and adaptability $[1,14]$. In fact, the professional identity of trainers is a topic that triggers intense sociological debate [16]. It is important to refer some interesting contributions for the development of this topic.

\footnotetext{
* Corresponding author. E-mail: marta@fpce.up.pt
} 
Vial [20] suggested two distinct logics based on which the trainer could be defined: the logic of control and the logic of evaluation. According to the logic of control, the trainer presents himself as master or guide, i.e., he holds the knowledge and defines a path for the trainees to follow. According to the logic of evaluation, the trainer follows and contributes towards the increased autonomy of the trainee. An approach particularly up-to-date if we take into consideration the modalities of adult training recently implemented in Portugal. These modalities contribute to a greater autonomy of the trainee and will be studied in depth later. Thus, we emphasize the importance played by the institutional bond in the predominance of one of these logics in the definition of the role of the trainer [16].

Another important contribution regarding the function of the professional activity was given by Géhin [9] after analyzing the interviews of forty trainers. The author concluded that the trainers pointed out three main functions of their activity. The integration function influences the behavior of the trainee, creating greater autonomy and responsibility but also a certain standardization. The psychological function supports the career development or the maturation of a project. Finally, the trainers interviewed mentioned the social function referring to the reinforcement of the internal cohesion of the institutions and the maintenance of social relations [9].

According to Lescure [10] several factors make the professionalization process of the trainer difficult. The diversified conditions under which the profession is carried out and the diversified professional profiles, the high work breakdown and the heterogeneity of the professionals involved are among them. It is important to refer that the actual concept of professional identity has undergone profound changes. The concept of professional identity as a process as opposed to a fact gave rise to several sociological studies in the professional evolution of trainers. For example, in the qualitative study performed by Géhin [9], previously referred to, the author discovered common aspects in the professional paths of the participants. The previous professional experience seems, above all, to play an important role if we consider that only $30 \%$ of the subjects studied enrolled directly in this profession. In general, the profession of trainer was considered a promotion in the career of a worker, a long time specialist in a specific function or an alternative after a period of unemployment. Nevertheless, the author warns against the probable changes in the way this profession is accessed, fore- seeable due the reduction of the duration of the workers' career, the increased complexity of professional courses and the increase of the level of initial education. Another common aspect found by Géhin [9] is the nonlinear evolution of the academic path of the trainers punctuated by moments of orientation, failure and abandonment. These academic paths occur parallel to the traditional educational system and in some ways come close to the paths followed by the trainees themselves. Finally, another common aspect is the use the trainers make of continuous training. The majority of the trainers interviewed by Géhin [9] attended short duration training courses and half attended longer training course, as an alternative strategy to the difficulties encountered in their initial academic path.

A recent study conducted by French, Canadian and Portuguese researchers analyzed the literature on this topic. The starting point was four base statements [6]: the fragmentation of the training profession; the difficulties reported by trainers in finding professional training in their everyday practices; a sometimes high rate of abandonment of the profession in the early stages; and the limited scientific knowledge of the profession. The first data collected in France shows the diversity of the activity and employment of the trainers [6], where the face-to-face pedagogical component does not represent more than $70 \%$ of the total working time. The data also reveals highly irregular work schedules, diversity of work places, also associated with travelling and overlapping of professional and private life.

\subsection{The Portuguese context}

In Portugal, the trainer status was legally defined in 1994 as someone who "in the performance of a training course, establishes a pedagogical relationship with the trainees, favoring the acquisition of knowledge and skills, as well as the development of attitudes and behaviors adequate to a professional deployment" [4, 5]. The Certificate of Professional Aptitude is mandatory since 1997. Nevertheless, it is possible to acquire the Certificate by equivalence of university degrees with specialization in teaching [17]. With regards to contractual and salary conditions, the general guidelines were defined by the competent institute but these do not always contribute favorably to the standardization of working conditions.

For a better understanding of the professional group of adult trainers in Portugal, it is unavoidable 
to refer the New Opportunities Initiative, launched in 2005 , with the aim of "broadening the minimum educational referential to 12 years of schooling for youngsters and adults" [2]. In organizational terms, it is important to refer the creation of new training facilities country wide, the establishment of two vectors - youngsters and adults - and the reinforcement of the Recognition, Validation and Certification of Skills (RVCS) modality.

Data collected in March 2011 revealed the existence of 459 New Opportunity Centers in operation and a total of 9069 people employed in the technical and pedagogical teams [15]. No official data was found regarding working conditions of these professionals.

As far as the main training modalities is concerned, the New Opportunities Initiative for the youngsters' vector foresees professional courses dedicated to learning and teaching of specialized arts. All these courses have a 3 year duration and the trainer plays a traditional role in the transmission of the knowledge defined for each training module. In the adults' vector two modalities are foreseen in which the trainer assumes the same role - Education and Training of Adults (ETA) and Modular Certified Training - with duration and flexibility adaptable to each case. Lastly, the most recent training modality - the Recognition, Validation and Certification of Skills - allows adults the recognition and certification of their knowledge and skills, acquired in a life-long career in informal learning contexts. In this process, the mission of the trainer is to "furnish the candidate with a method of analysis of his experience and a manner in which to translate it in terms that will allow its validation" [11].

\section{Method}

\subsection{Participants}

First, it was applied a questionnaire to 72 trainers in a training center ( 31 females and 41 males, Mage $=42$, age range: $24-71$ years). Later 10 of these trainers also collaborated in this study (7 males and $3 \mathrm{fe}-$ males, Mage $=43,8$, age range: $28-67$ years, 9 are independent workers and 6 work exclusively as trainers) and participated in an individual interview to understand their professional paths and their work schedules. The study culminated with collective interviews held with 6 trainers ( 4 females and 2 males, Mage $=34$, age range: $27-35$ years), which allowed a more in-depth knowledge of the professional activity of this group.

\subsection{Data collection}

In order to learn about the activity of the trainers, different strategies of data collection were used. Initially the INSAT [3] inquiry was applied to the trainers with the aim to study their work, the conditions and the perceived relationship with the health of the workers.

These were followed by exploratory interviews held with 10 trainers which provided a significant set of data to be transferred back to the professional group. These trainers were also required to fill in a work schedule based on the records of their diaries for two specific weeks.

Finally, 6 trainers volunteered to participate in 4 collective interviews to learn about their activity through their own descriptions. Trainers were required to fill in a detailed real work schedule for one week, where they should also include the «small» activities which are normally not accounted for.

This data was collected from January 2008 to June 2010, in a professional training center in the north of Portugal [8, 13, 18, 19].

\subsection{Procedure}

The selection of participants was preceded by a meeting with the person responsible for the Professional Training Centre, in which the aim of the study was explained and authorization was obtained. The inquiries were distributed to the trainers who volunteered to fill them in autonomously.

The exploratory and collective interviews, as well as the filling in of the respective work schedules, were carried out by trainers that volunteered to continue in the study.

All interviews were held in the training center, recorded on audio and entirely transcribed for future content analysis.

\section{Results}

\subsection{Part One: INSAT}

From the INSAT application results, $55 \%$ of the inquired practice their activity as independent workers and $40 \%$ are exclusively trainers. About $82 \%$ of the trainers inquired have been in the profession for less than 5 years. 


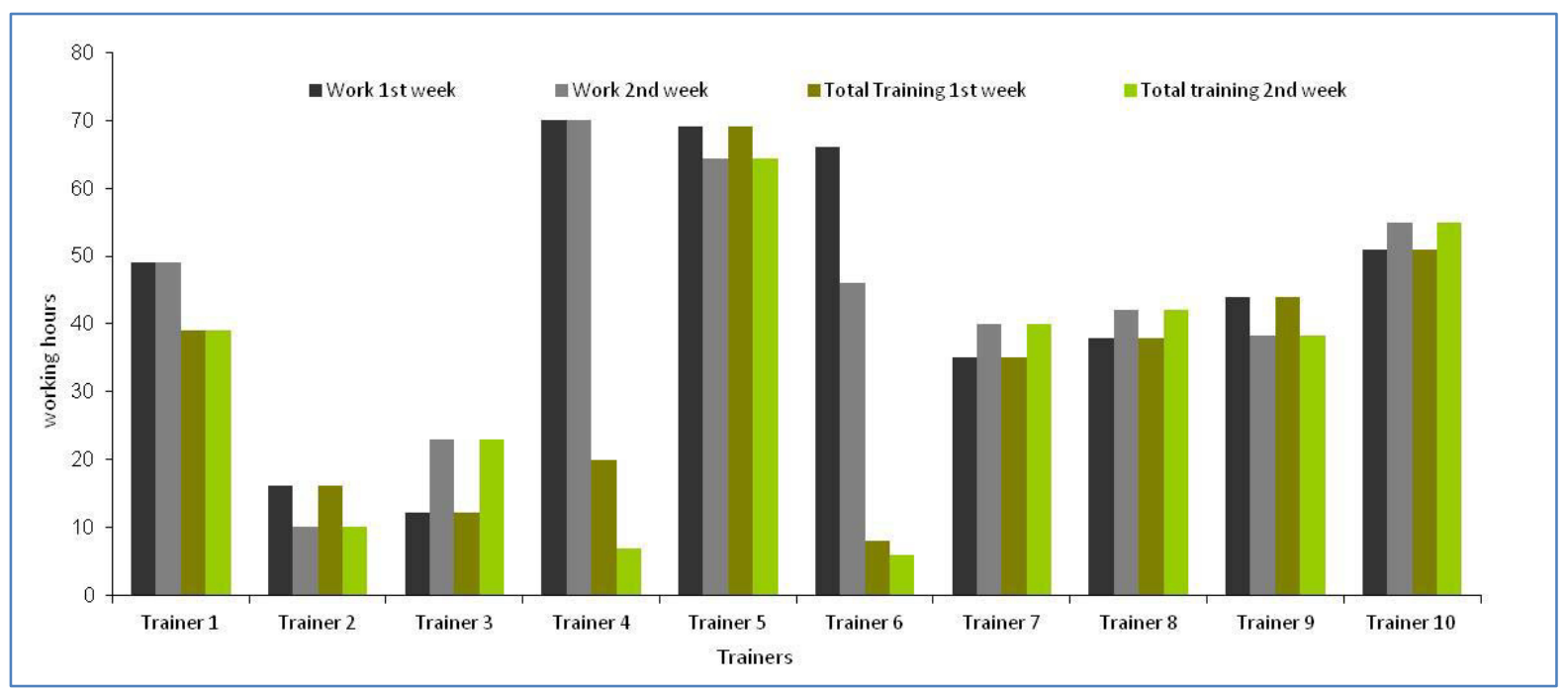

Figure 1 - Weekly working times registered in "personal diaries" by the trainers interviewed

With regards to working time, the inquired trainers estimated that they work, on average, 35,8 hours per week. However, it is important to refer that a nonnegligible percentage of the trainers $(20 \%)$ reported over 50 working hours.

The INSAT analysis allows us to learn about the main characteristics and constraints that trainers associated with their professional activity. Among the main constraints of the physical environment identified by trainers are the aggressive or annoying noise $(21,4 \%), 38,8 \%$ referred standing up for long periods of time and moving around. The need to travel frequently was also mentioned $(36,8 \%)$.

The INSAT analysis also reveals the high degree of independence and initiative associated with this profession. However, the data cannot be dissociated from the fact that $65 \%$ of the trainers mention that they frequently surpass the normal working times; $60 \%$ mention the need to skip or reduce meal times; $59 \%$ mention that they are exposed to the necessity of solving problems unassisted; and $46 \%$ refer the need to frequently perform several tasks simultaneously.

Another constraint referred by the trainers is the contact with the public. Though, 34,3\% consider they have to endure the demands of their target-public; $47,1 \%$ confirm that they have been subject to difficult public relationships situations; and, out of the 72 trainers, $39,7 \%$ and $27,9 \%$ feel exposed to the risk of verbal and physical aggression from the public, respectively.
Finally, from the main health risks perceived by the trainers, the following stand out: stress (40\%), irritability $(25 \%)$, general fatigue $(25 \%)$, eye-sight problems $(25 \%)$, anxiety $(23,6 \%)$, back ache $(23,6 \%)$ and headaches $(20,8)$ (Fig.1).

With the exception of the eye-sight problems, trainers consider that these risks are caused or aggravated by their professional activity.

\subsection{Part Two: Interviews}

The individual exploratory interviews allowed a deeper knowledge of the professional paths and of the organization of the work schedules of the trainers. The analysis of the work schedules registered by the trainers in their diaries over a two week period revealed great variability, both inter and intra individual, as illustrated in Figure 1.

The interviews also revealed the great diversity of tasks performed by trainers in their daily routine, namely the preparation of sessions, the elaboration of exercises, the requisition of materials, class meetings, writing reports, follow up of traineeships, planning of visits, among other.

\subsection{Part Three: Group Interviews}

The analysis of the collective interviews allowed an in-depth study of three aspects: contractual forms and employment conditions; working times; and specificities of the training activity according to the training modality chosen. 


\subsubsection{Contractual forms}

The most common option to contract trainers is through a service contract. There are up to 4 different types of contract according to training modalities and type of work. Generally speaking, contracts are defined by the number of training hours foreseen for the specific course or based on an estimate of the work to be carried out over a yearly period. The hourly amount paid also varies according to the type of work contracted (the training sessions are better paid than technical work) and to the geographic zone where the work is performed.

Payments are monthly and based on the number of effective working hours, taken into consideration the different aspects already mentioned (type of training, characteristics of the work, location).

\subsubsection{Working time}

As far as working time is concerned, it is important to reiterate the great inter and intra individual diversity revealed by the individual interviews. Nevertheless the trainers interviewed refer an average of 54,3 working hours per week, including travelling time between their homes and respective work locations. The average daily working time is 8,2 hours. However some of the trainers mention over 12 hours daily in the training center. It is also important to underline the high number of continual sessions, without breaks included in the schedule.

The actual working time analysis can be enriched by the study of the relationship between contractual terms and remuneration. In order to do so, trainers were asked to organize the activities performed according to the remuneration factor, i.e., if they are subject to a specific remuneration. The result is presented in Figure 2.

All activities referred by trainers were included in this analysis, with the exception of preparation of sessions, evaluation of trainees - preparation and evaluation of trainees - evaluation/correction due to the controversy surrounding these criteria. Although trainers consensually consider these tasks nonremunerated, the contractual terms consider that the hourly training rates include the preparation and evaluation times.

The hours considered without specific remuneration are the hours spent on meetings of the pedagogical team and meetings between trainers and representatives of the training center. From this analysis it is possible to conclude that, on average, in the week analyzed, about $17 \%$ of the working hours of these trainers were not remunerated.

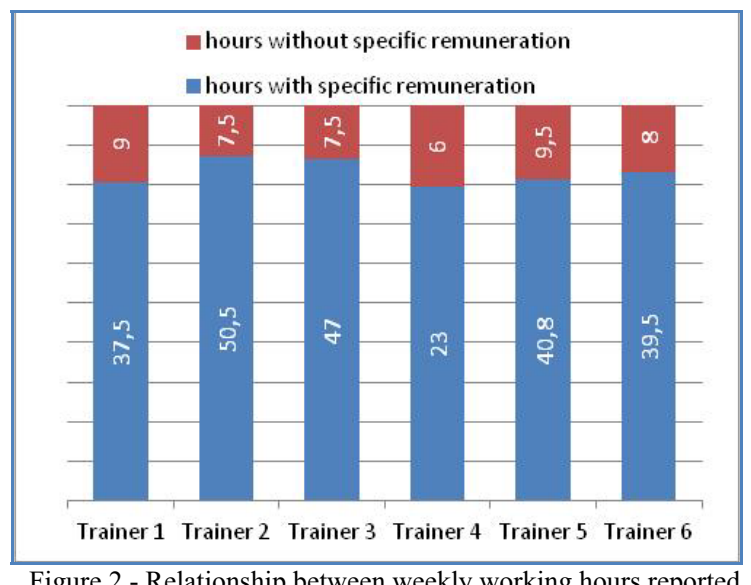

Figure 2 - Relationship between weekly working hours reported and remuneration

\subsubsection{Organizing activities}

Collective reflection on the way the trainers organize their tasks allowed to identify 21 different activities, namely the preparation of training sessions, requisition of materials and follow up of traineeships. Eighteen of which are performed by all trainers involved in the collective interviews.

Trainers do not organize their tasks according to two big groups of tasks that are usually prescribed: (1) pedagogical contact and (2) other tasks, such as the preparation and evaluation of those contact moments. On the contrary, the organization of their activities reflects the division between the two main training modalities carried out in this particular training center - ETA and RVCS - and the different organization and constraints of each modality stands out.

Trainers involved in both modalities recognize clear differences in the conditions and demands on everyday activities due to training characteristics, specificities of the target-public, remuneration conditions and time dedicated to each of them. For these trainers, even the actual sessions varies according to the modality in which they are included. On the one hand, the sessions included in the RVCS present a rigid and complex structure that respects the predefined schedule - the number of sessions dedicated to the presentation of the referential, the demonstration of skills, complementary training and accompanied individual work. So, these sessions are, in the trainers' opinion, less demanding on the preparation level. As far as the preparation of sessions of ETA courses is concerned, it involves greater effort since there is the need to adapt each session to each group as well as the logic of continuous upgrading. This preparation tends to be done out of the training center, in less 
rigid timetables, with the exception of the sessions that require the requisition of materials or preparation of equipment on the spot.

It is also important to refer that the activities that trainers consider more difficult are the analysis of portfolios and attending adults that belong to the RVCS modality. The first comprehends the attentive reading of the autobiographies written by the trainees and the validation of the correspondence with the key-skills referential. This analysis culminates in a set of upgrading suggestions which are transmitted to the trainee in an individual meeting. The time consuming issue is not the time trainers spend analyzing the portfolios, but the need to adapt to the rhythm of each trainee, the repetitive analysis of each portfolio and the coordination between the trainers of different areas.

As far as meetings with adults is concerned, it is almost impossible to predict the duration of each meeting and the ever increasing number of cases portfolios are copied makes the confrontation with trainees mandatory. Furthermore, as both activities are considered technical work, they are subject to inferior remuneration and are usually more time consuming than the stipulated in the annual contract.

\section{Discussion}

\subsection{Trainers' Working and Employment Conditions}

The data collected reflects the inherent complexity of the trainers' activity which, in the case of adult training, is intensified by the diversity of the trainees' background, educational level and by a weaker authority relationship between the trainer and the adult trainee [12]. Additionally, the diversity of activities presented above contributes to this complexity, as has been referred by previous studies $[6,16]$.

Regarding working conditions, the issue is not the long weekly working hours reported by some trainers, but their organization. To optimize the travelling time to the training center and to facilitate the conciliation with other professional activities, trainers deliver up to 4 continuous sessions. Generally, there are no breaks between sessions and the sessions have the same content, becoming difficult to distinguish one from another. Another issue to take into consideration in the organization of timetables is the travelling time between different locations where the classes are held. This professional travelling, the cost of which is seldom covered by the contracted remuneration, is one of the main constraints pointed out by the trainers.

The contractual terms identified attest the precarious labor conditions these professionals are subjected to, namely due to the various short-term contracts they sign simultaneously and the number of activities performed without remuneration. In light of the above, trainers face a dilemma they have to manage on their own. If trainers do not agree with the unpaid work they are forced to do, the only way training centers have to accomplish their goals is to add hours to the annual contracts. However, one may say that the renovation of their contracts, although precarious, may depend on their subjection to the conditions imposed.

Beyond the negative consequences this precariousness might have on the trainers' health and wellbeing, it has also implications on the pedagogical quality level. It restricts the preparation of specific pedagogical material and makes it difficult to build solid support relationships between colleagues [12]. The group of trainers interviewed attributed great importance to the relationship within the pedagogical team, which they try to instigate by scheduling team meetings in accordance with the timetables of the various trainers and by using tools that enable nonpresencial communication between trainers.

\subsection{The new training modalities and training paths}

The emergence of new training modalities in the Portuguese training system is paradigmatic, presenting new challenges both to trainers and training centers. One of these modalities is the RVCS, a modality, which increases the autonomy of the trainee and gives special attention to the target-public. A public composed mainly of adults for whom the regular educational system did not result [12]. A group weakly motivated towards the project, attending classes most of the time because they are obliged by the government.

The analysis of the data collected also emphasizes recent modifications on human resources recruitment and trainers contractual terms in the sector. These changes, usually imposed on training centers, also translate into changes on the professional path of the trainer. The trainers interviewed present a similar academic and professional path, holding, at least, a university degree. As far as antiquity in the profession is concerned, based on the data collected through the INSAT, $82 \%$ of the trainers inquired have been in the profession for less than 5 years. 
These professional paths are in clear opposition to the path identified by Géhin [9] whereby it was a promotion after a long workers career or an alternative after a period of unemployment. In fact, these professional paths personify the likely transformations mentioned by Géhin [9] in the access to the profession, introduced by the increased complexity of the professional training courses and the increase of the entry level. Given the political and economic situation in Portugal, it is important to refer the difficulties met by professionals in this sector in finding employment in other training modalities, apart from adult training, in which a large investment was recently made.

Finally, it is important to emphasize the trainers' efforts to organize their activities according to the main training modalities currently in place in Portugal: ETA and RVCS. Two modalities that reveal differences in terms of the activities involved constraints and time demands. One can say that this distinction personifies, in certain aspects, the differences between the logics of control and evaluation, previously referred to in this paper [20]. Thus, more than generally identifying the demands imposed by each of the tasks performed, trainers consider them in function of the training modality they are inscribed.

\section{Conclusion}

Although it is still necessary to develop and deepen the scientific knowledge about trainers' activity in Portugal, the present study represents an interesting contribution to furthering the understanding of this reality.

It is important to emphasize that all the investment made in the qualification of the Portuguese is not reflected on the working and employment conditions of the trainers. The inexistence of stable work contracts, the long working hours, the need to conciliate the available time of the adults in training with the goals of the training centers, together with the political instability underway in our country and eventual repercussions associated with investment in this field, contribute to the degradation of working and employment conditions of trainers.

It is also important to recognize that adult training [14] S. Morata and E. Rastoin, "L'autre" et "le même" de l'identite profissionnelle : le cas de la polyvalence, in : La polyvalence : quelle identité profissionnelle ?, Université de Provence, 2006

[15]Novas Oportunidades (2011). Informação estatística. Consultado em 13 de Julho de 2011 http://www.novasoportunidades.gov.pt/np4/estatística. in Portugal is going through a turning point, which reflects, not only a new human resources management technique adopted by the training centers, but also the role the trainer is expected to play in each training modality, taking into consideration the various contradictions and dilemmas with which he is ultimately confronted.

\section{References}

[1] M. Abbadie Dalemont and L. Algrin, L'identité professionnelle du formateur, in: La polyvalence: quelle identité professionnelle ?, Université de Provence, 2006.

[2] ANQ (2010). Novas Oportunidades: Aprender compensa. Lisboa: ANQ, I. P. Consultado em 24 de Julho, 2010. http://www.novasoportunidades.gov.pt/

[3] C. Barros-Duarte, L. Cunha and M. Lacomblez, INSAT: uma proposta metodológica para análise dos efeitos das condições de trabalho sobre a saúde, Laboreal, 3, 2 (2007) , 54-62. http://laboreal.up.pt/revista/artigo.php?id=37t45nSU54711231 $1: 499682571$

[4] Decreto Regulamentar n66/94 (94-11-18) 6855-6887

[5] Decreto Regulamentar no 26/97 (97-06-18) 2948-2950

[6] C. Delgoulet, Conditions de travail et de santé des formateurs en formation professionnelle et lycée professionne,. Séminaire ECI, Université Paris Descartes, 2008.

[7] C. Dubar cit in E. Pottier, Les formateurs d'adultes un group professionnel segmente en tension entre deux mondes. Thèse de doctorat de sociologie. Université de Versailles SaintQuentin-en-Yvelines, 2005, p.8.

[8] A. Ferreira, Análise colectiva da actividade dos formadores em Portugal: a diversidade de actividades, o impacto das condições contratuais e as implicações para a saúde, Master Dissertation, Universidade do Porto, 2010

[9] J.-P. Géhin, Constrution du groupe professionnel des formateurs et regionalization des politiques de formation. In E. Lescure \& C. Frétigné (Eds). Les métiers de la formation, Presses Universitaires de Rennes, Rennes, 2010, pp. $55-66$.

[10]E. Lescure, Introduction: Un ensemble hétèrogène. Éléments de littérature sur les métiers et les agents de la formation, in: E. Lescure and C. Frétigné (Eds.), Les métiers de la formation, Rennes, 2010, pp.7-16.

[11]N. Mariani and C. Xueref, Formateur / accompagnateur VAE dans le champ de la Santé: quelle posture?, in: La polyvalence: quelle identité professionnelle?, Université de Provence, 2006.

[12]K. Messing and A. Seifert, "on est là toutes seules", Constraintes et strategies des femmes en contrat à durée déterminé dans l'enseignement aux adultes, Travailler, 7 (2002), 147166.

[13] A. C. Monteiro and M. Santos, Primeiras análises do trabalho do formador: Aplicação do questionário INSAT - Inquérito Saúde e Trabalho, in: $5^{\circ}$ Fórum Jovens Cientistas, FPCEUP, 2010 .

[16]E. Pottier, Les formateurs d'adultes un group professionnel segmente en tension entre deux mondes. Thèse de doctorat de sociologie. Université de Versailles Saint-Quentin-enYvelines, 2005.

[17]Portaria n $^{\circ} 1119 / 97$ « D. R. I Série B », 256 (97-11-05) 60996100 . 
[18]M. Santos, J. L. Costa, and M. Lacomblez, Les conditions de travail et de santé des formateurs en formation professionnelle: premières données et premières analyses relatives au cas portugais, in : Séminaire ECI : Conditions de Travail et de santé des formateurs en formation professionnelle et lycée professionnel, Université Paris Descartes, 2008.
[19]M. Santos, S. Gomes and M. Lacomblez, Les conditions de travail et de santé des formateurs en formation professionnelle: observations relatives au cas portugai, in: Séminaire «L'analyse des pratiques des enseignants et formateurs», Université Paris Descartes, 2009.

[20]Vial, 2001 cit in M. Abbadie Dalemont and L. Algrin, L'identité professionnelle du formateur, in : La polyvalence: quelle identité professionnelle ?, Université de Provence, 2006. 